\title{
Enhancing the Learning and Teaching of Public Speaking Skills
}

Johanne Jean-Pierre, Sabrin Hassan \& Asha Sturge

To cite this article: Johanne Jean-Pierre, Sabrin Hassan \& Asha Sturge (2021):

Enhancing the Learning and Teaching of Public Speaking Skills, College Teaching, DOI: 10.1080/87567555.2021.2011705

To link to this article: https://doi.org/10.1080/87567555.2021.2011705

曲 Published online: 06 Dec 2021.

Submit your article to this journal $\pi$

Q View related articles ¿

View Crossmark data ð 


\title{
Enhancing the Learning and Teaching of Public Speaking Skills
}

\author{
Johanne Jean-Pierre ${ }^{\mathrm{a}}$ (D) Sabrin Hassan ${ }^{\mathrm{b}}$ (D) and Asha Sturge ${ }^{\mathrm{a}}$ (D)

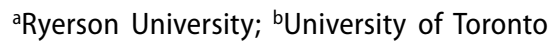

\begin{abstract}
Various pedagogical strategies promote the development of communication skills that enable graduates to leave their mark and make positive changes in society. This article focuses on instructional lessons learned from undergraduate student perspectives of the pedagogy of the lightning talk, a three-minute oral presentation delivered without the use of supporting materials and without audience engagement in a noncompetitive environment. Drawing from the data of a mixed-methods study conducted at a metropolitan university, this article highlights key pedagogical lessons. Students' responses indicate that instructors can implement instructional strategies that enhance students' preparatory work and accessibility. Students also shared that they developed valuable public speaking-related skills. Overall, the findings can inform how instructors can enhance learners' communication skills with inclusive teaching strategies.
\end{abstract}

\section{KEYWORDS}

Communication skills; higher education; lightning talk; oral presentation; public speaking

\section{Introduction}

Individual and group oral presentations are pedagogies that provide an opportunity to strengthen public speaking skills. Students' disposition toward oral presentations can vary widely, from those who express comfort, ease, and confidence to those who perceive this assessment as a daunting challenge. Likewise, during students' oral presentations, instructors can sometimes witness a range of occurrences, such as stage fright, memory loss, and avoidance of eye-contact, but also moments of joy, moving storytelling, and pride. The range and frequency of previous oratory experiences, the extent of pre-university degree preparation, and individual personality traits contribute to various outputs. More specifically, the intensity of students' apprehension and the range of performances are generally contingent on oral presentation preparatory work. This preparation inherently involves students' seeking, selecting, organizing, and prioritizing the relevant content, and fashioning how they will convey their ideas and practice their piece. Yet some students may struggle with the aforementioned preliminary work, which can sometimes result in vague, aimless, monotonous, or repetitive oral presentations. Thus, learning from students what can foster public speaking delivery and preparatory work is worthwhile.
This article derives instructional lessons from students' perspectives of the pedagogy of the lightning talk. The purpose of this study was to examine undergraduate students' insights and responses following the application of the pedagogy. In this article, a lightning talk is defined as a short, time-limited, oral presentation on a subject that is completed without the use of supporting materials, such as PowerPoint slides, notes, or electronic device (Jean-Pierre et al. 2020). Across courses and disciplines, a common teaching goal of this pedagogy is the development or enhancement of public speaking skills, but this study did not aim to assess this learning outcome. Rather, our research question is: What are undergraduate students' perspectives of the pedagogy of the lightning talk? Drawing on a mixed-method study conducted at a metropolitan university in 2019, we present students' responses to the lightning talk and how they can assist instructors who want to promote public speaking skills with the assignment of oral presentations. This study is relevant because the students' perspectives of their learning provide valuable instructional lessons for educators and curriculum designers. In the subsequent sections, we present an overview of the literature regarding inclusive pedagogy and oral presentations, followed by the application of the 
pedagogy in two different undergraduate courses, the methodology of the study, the findings, and the conclusion.

\section{Literature review}

\section{Inclusive pedagogy principles}

In this study, we designed and implemented the lightning talk with the goal of creating and maintaining an accessible classroom environment. Inclusive pedagogy is critical to create educational environments that foster accessibility for students with disabilities (Grier-Reed and Willliams-Wengerd 2018). Several inclusive teaching strategies are encouraged in higher education and are integral to universal design for instruction (UDI). Universal design was first applied in architecture to create accessible environments and buildings for individuals with disabilities, which are often beneficial for others as well (Silver, Bourke, and Strehorn 1998). In the field of education, universal instructional design posits that accessibility should be an integral part of curricular and pedagogical planning, and must anticipate the needs of different learners (Orr and Hammig 2009; Silver, Bourke, and Strehorn 1998). To promote universal design in education, it is essential to incorporate several means of representing course content, to include several means of expressing one's understanding of course material, and to recognize several means of engagement (Zeff 2007). Some pedagogical strategies derived from this framework include precise assignment instructions (Orr and Hammig 2009), scaffolding (Silver, Bourke, and Strehorn 1998), or videotaped presentations (Orr and Hammig 2009).

\section{Oral presentations and the pedagogy of the lightning talk}

Alongside the goal of advancing students' writing skills, faculty and instructors often aim the development of oral presentation skills to promote a range of communication aptitudes (Jarvis 2004; Murillo-Zamorano and Montanero 2018). Several aspects of postsecondary oral presentations have been explored in the recent literature, such as oral presentations' assessments (Barry 2012; De Grez, Valcke, and Roozen 2012; Murillo-Zamorano and Montanero 2018; Murphy and Barry 2016; Ritchie 2016; Vahid 2017), oral presentations' performance factors (Liang and Kelsen 2018), or the use of technology to develop oral presentation skills (Gwee and Toh-Heng 2015). Different oral presentation formats have been explored that involve the use of supporting material and technology (Klentzin et al. 2010; Moulton , Turkay, and Kosslyn 2017). While the lightning talk may seem like other oral presentations, its goals and modalities differ. The absence of supporting materials distinguishes the lightning talk in this study from the Pecha Kucha short presentation, which involves visual supports with twenty PowerPoint or Prezi slides (Klentzin et al. 2010). It is slightly longer than an elevator-pitch, which is also conducted without supporting materials, and has the purpose of selling a service or an idea with a short and compelling presentation in 30 to 60 seconds (Cox and Marris 2011; Pagana 2013; Simpson 2016). The widely known Three Minute Thesis (3MT) competition invites graduate students to present their research concisely and effectively in three minutes ( $\mathrm{Hu}$ and Liu 2018), and rewards are often given to the best presenters. In this article, the lightning talk is an assessment assigned in a noncompetitive environment as a reflexive pedagogical strategy before and after the oral presentation, in order to support undergraduate students' learning how they personally engage in public speaking. While students are encouraged to present with the best of their abilities in a compelling manner, the self-discovery process, and the activation of metacognitive skills throughout the process, constitute important components of the pedagogy of the lightning talk, in contrast to selling an idea or a product during an elevator-pitch or attempting to win a reward during a $3 \mathrm{MT}$ competition.

\section{The application of the pedagogy of the lightning talk in two different courses}

The lightning talk, a three-minute oral presentation without the support of PowerPoint slides, notes, or any other technological support (Jean-Pierre et al. 2020), was used in two different courses. In both courses, the common and primary learning outcome of this pedagogy was the development of public speaking skills. We suggest that by removing the use of visual supports, students had a greater opportunity to learn how to make eye-contact with their audience while using persuasive language to convey their message. In order to align this assessment with inclusive pedagogy principles, students could elect to present in front of the instructor alone or at the back of the classroom in-front of a small group. In both courses, the preparatory work and reflection regarding the process of this oral presentation were emphasized before and after the delivery of the presentation through in-class discussions. Students were 
encouraged to present substantive content with clear, concise, and persuasive communication. The instructions regarding the required content differed in each course because in one course, students were required to present an advocacy statement, while in the other, they were required to demonstrate their understanding of a peer-reviewed article in a compelling manner.

Course 1: In order to foster advocacy skills, students were required to imagine that they were introducing themselves to the principal or vice-principal of a school in the hallway after being recently hired. In three minutes, they were expected to discuss the following: a) an explanation of the core components of their profession; b) a summary of their personal strengths and competencies; and c) a statement that highlights how they will be an asset to the school community.

Course 2: In order to strengthen literacy skills, after reading a peer-reviewed article, students were asked to: a) synthesize the key reasoning and arguments of the peer-reviewed article; and b) convince their classmates that they should take the time to read the article.

In both courses, instructors prepared students to be successful by leading them in breathing exercises and vocal warm-up exercises, standing up to help them familiarize themselves with their own voices. In addition, instructors led peer-activities where students could present and support each other with constructive feedback. Students were also encouraged to practice outside of class in front of friends and family members, in front of a mirror, or with a cell phone. This study does not focus on the objective evaluation of learning outcomes of the pedagogy of the lightning talk; rather, we draw instructional lessons from students' perspectives.

\section{Methodology}

This study aimed to acquire instructional insights from students' perspectives of the pedagogy of the lightning talk. The research question was: What are undergraduate students' perspectives of the pedagogy of the lightning talk? The study was conducted at a Canadian metropolitan university in April 2019. The first author of this article was the instructor in one of the courses, and the other two coauthors were research assistants who participated in data collection, data analysis, and dissemination. The purposive sample of this study included 70 undergraduate students registered in both courses. Most of the participants were enrolled in the bachelor's degree of child and youth care, early childhood studies, and other allied disciplines.
We elected to use a mixed-methods research design to mobilize the strengths of both quantitative and qualitative methods (Bamberger and Mabry 2019) and to gather explanations of the quantitative measures. The open-ended questions aimed to capture the insights and rationale of students, which is not possible with solely quantitative data. It was important that we collect a wide range of students' viewpoints. We wanted to gather the input of highly motivated and engaged students who tend to communicate with instructors openly, as well as that of students who are less expressive or forthcoming, and who may prefer the anonymity of an online survey. To gather the viewpoints of the largest number of students, we utilized a post-test online questionnaire, including quantitative measurements (closed questions) and qualitative measurements (open-ended questions) regarding stress, preparation for the lightning talk, the skills and competencies acquired, and accessibility. The closed-ended questions were designed with a Likert-scale (strongly agree to strongly disagree) and descriptive statistics are mobilized in this article.

To analyze the qualitative data, and to explore the main learning experiences of the lightning talk reported by students, we engaged in deductive thematic coding with the qualitative software NVivo. We conducted several cycles of coding to familiarize ourselves with the dataset, recognize recurrent topics, create and refine categories, and identify salient themes (Saldaña 2016). To achieve triangulation and ensure the methodological rigor of narrative interpretation, all three authors conducted coding and data analysis (Bamberger and Mabry 2019). This research project was approved by an institutional ethics review board. In the following section, we use pseudonyms to maintain participants' confidentiality.

\section{Findings}

The findings reveal that students would prefer that, prior to their presentation, instructors provide precise instructions, encourage frequent practice to facilitate their preparation, and explicitly teach emotional self-regulation. Moreover, students suggested certain adaptations that can support the learning experience of students with and without disabilities. Finally, following the completion of the lightning talk, participants shared a belief that they developed their critical thinking skills, consolidated the flexibility and adaptability of their communication skills, enhanced their personal and professional confidence, and expanded their advocacy skills. We suggest that these findings can inform instructors' inclusive pedagogical 
strategies, as they strive to promote the development of transferable communication skills that can be mobilized to speak publicly in a clear, concise, and compelling fashion in various personal and professional contexts. The transferable skills developed can support college and university graduates' transitions into their respective careers and professional development in various contexts.

\section{Students' recommendations to facilitate their preparation}

With a closed-ended question, students were asked about the duration of their preparation: less than one hour, 1-3 hours, 3-5 hours, 5-10hours, or more than 10 hours. Most students $(71.88 \%)$ reported that they invested between one and five hours of preparation for the lightning talk. They were also asked the following open-ended question: What would be useful for you to be better prepared for lightning talks both at school and in the field? Participants shared that practicing in and out of class, being taught explicitly how to regulate their emotions, and receiving more detailed instructions would have strengthened their oral presentation preparation.

\section{Receiving specific instructions}

Through the qualitative data, we noted that some students wished they had received precise instructions to conceive their lightning talk. August wanted more accurate guidance and hoped for "exact specifications on what is to be submitted." Students like Sage wanted "a better outline of the structure of lightning talks." Jules shared that someone else delivering an example of a lightning talk could help students grasp the assignment's expectations, stating, "It would be helpful if I can get an example of this assignment." These insights underline that some students may benefit from thorough instructions, and ideally an example of a lightning talk, in order to clarify the possibilities and expectations.

\section{Learning how to regulate one's emotions}

Students can experience high levels of stress, stage fright, and nervousness during an oral presentation. Through their narratives, a few students stated that being able to manage their emotions facilitated the process of presenting in front of the class. As Rain said, it is beneficial to know "how to calm down in front of people." Similarly, Madison said, through the process, she learned that "I am able to slow down my speaking even when I am nervous." In both groups, instructors engaged in breathing exercises and peer-activities to strengthen persuasive public speaking skills. These narratives indicate that it is equally important and valuable to work on developing stress-management techniques to alleviate the nervousness and apprehension associated with oral presentations.

\section{Practicing in and out of class more frequently}

The strategy most reported by students to prepare for the lightning talk presentation is practicing frequently in and out of class with family and friends. For instance, Storm suggested that "practicing with peers" would be a good strategy for preparation. Sunny suggested that "practicing in class first with my peers with different school-related scenarios beforehand" could have enhanced her level of confidence in her preparation. Like Storm and Sunny, other respondents spoke about how practicing outside of class with peers and family members prior to the presentation buttressed overall preparedness and confidence.

\section{Students' suggestions for the adaptations of oral presentations}

A majority of students (74.6\%) responded that they strongly agreed or agreed that "Thinking about standing in front of the classroom individually caused me stress." Students were given the closed-ended statement: "You have unique circumstances that made this assignment more challenging and could have benefited from some form of accommodation." The stress combined with challenging circumstances can explain why a large proportion of students (49\%) reported that they strongly agreed or agreed that they could have benefited from some form of accommodation, because they had unique circumstances that made the lightning talk more challenging. Nevertheless, based on the instructors' records, a smaller proportion of students were registered with the accessibility office, compared to the number of students who provided this response. Hence, the following recommendations include the suggestions of students who are not formally registered with accessibility services even if they have a disability, and students who do not have a disability but would see their learning experience as being enhanced by the following adaptations. All respondents were asked the open-ended question: "If applicable, what accommodation strategies would you have liked to have had access to while completing this assignment?" Participants shared that they find 
memorization challenging and valued the possibility to present alone or in a small group.

\section{The challenge of memorization}

Memorization is challenging, even in the context of a short, three-minute presentation. Several students expressed that they believe that access to notes, cue cards, or a script would have assisted them. Marley said that notes constitute a form of reassurance, and Ode and Florian said that they can help as a referral in case they forget part of their presentation. Perry shared that "reading off a sheet of paper" would have been helpful. This preference for reading or referring to the presentation reflects students perception of their proficiency, confidence, and level of comfort when memorizing their scripts. For instance, Chidi reflected that instructors should have allowed students "to have side notes with us rather than to memorize". Memorization can increase the stress level of some students; Emery disclosed that "I would like a paper with notes to ease the stress of trying to remember everything". It is relevant to highlight that less than a third of the class reported that they memorized their text for more than three hours before their presentation, indicating that students may underestimate the time required to prepare the lightning talk.

\section{The ability to present alone or in a small group}

A few students expressed that they would have liked to present alone or in a small group, rather than in front of the whole class. This is not surprising, given that nearly three quarters of the students shared that the thought of standing in front of the classroom individually is stressful. Raven stated that she would have preferred the option of "completing the talks with small groups rather than in front of a huge class". Similarly, Storm, Joey, and Cleo suggested that they would have appreciated the option to present alone with the professor in the hallway or in an office. Presenting in front of the classroom can make them nervous, students explained, especially in larger classes.

\section{Students' perception of their skills development}

Students were asked to respond to the following closed-ended statement: "The lightning talk promotes high level skills in different areas such as: advocacy, critical thinking, formulating persuasive arguments, or professional confidence." Students were also asked to respond to the following closed-ended statement: "After completing this presentation, I believe that I can spontaneously provide concise responses in range of contexts and situations, and I believe that I am better prepared for an 'elevator pitch', 'hallway encounter', or an interview regarding a certain topic." All the participants were asked the following open-ended question: "What have you learned about your own strengths, interests, ideas?"

\section{Enhancing critical thinking and creativity}

An overwhelming majority of respondents (89.23\%) reported that they strongly agree or agree that the lightning talk fosters critical thinking skills. Many participants $(86.15 \%)$ maintained that they strongly agree or agree that the lightning talk fosters the skills to formulate persuasive arguments. Hudson shared that the lightning talk built on previous "critical reflection" exercises in his educational journey. Other students experienced moments of self-discovery regarding their creativity. For instance, Hayden shared that, while she does not express herself frequently, with the lightning talk, she realized that she can be creative: "I can come up with content to present, and I have many ideas that I do not always express out loud." West also stated that the lightning talk contributes to fostering creativity, and Xoan concluded that, compared to other students, her presentation was distinctive: "I have unique perspectives." Perhaps organizing, prioritizing, and refining the ideas conveyed in a short period of time, without visual supports, contributes to students' belief that they developed their critical thinking skills and creativity.

\section{Consolidating adaptable and flexible communication skills}

More than half of the participants (58.46\%) indicated that they strongly agree or agree that, after completing the lightning talk, they can provide concise responses in a range of contexts and situations. A large proportion of participants (65.63\%) declared that they strongly agree or agree that they are better prepared for a "hallway encounter" or an interview. Following the lightning talk, Blue realized that her communication skills extended to shorter and more concise presentations: "I have learned that my abilities in creating a concise presentation are greater than I previously estimated." For Phoenix, the lightning talk revealed that it is possible to plan and understand content that is subsequently presented in a short format. She learned that "you can prepare a presentation of three minutes and understand it, so you can talk about it." Aiden noted that the lightning talk built upon the skills acquired in previous individual and group 
presentations completed in her program, underscoring how even experienced learners can benefit from the lightning talk and use it to strengthen their abilities.

\section{Building personal and professional self-confidence}

More than half of the respondents (55.39\%) indicated that they strongly agree or agree with the following closed-ended statement, "After standing in front of the classroom individually, I feel more confident." In some instances, respondents' self-confidence is related to juggling several tasks during the lightning talk presentation. For instance, Gene came to the realization that "I am able to project my voice despite being nervous." For some students, this resulted in moments of self-actualization and personal pride in their ability to overcome challenges. Joey stated that "I learned that, when need be, I can conquer through and be resilient." A vast majority of students (93.76\%) affirmed that they strongly agree or agree with the following closed-ended statement: "The lightning talk promotes high level skills for my discipline in terms of professional self-confidence." For instance, Chi affirmed that "I learned that I am more confident in my role as a professional." Building personal and professional self-confidence can propel adult learners to overcome personal fears, and gather the courage to lead dynamic oral presentations and projects in their current or future careers.

\section{Establishing advocacy skills}

Most participants $(89.07 \%)$ revealed that they strongly agree or agree with the following closed-ended statement: "The lightning talk promotes high-level skills for my discipline in terms of advocacy." This does not mean that the assignment itself suffices to develop advocacy skills, but that it can be a starting point to encourage student reflections and the development of these skills, as demonstrated by Kamryn: "I learned that I need to learn how to advocate more effectively." Morgan shared that the lightning talk enabled her to become aware of "the importance of advocacy and speaking up." Advocacy skills can be mobilized in the workplace for oneself or service-recipients, or in unforeseen situations that require speaking out, and they can be fostered among undergraduate students through the lightning talk (Jean-Pierre et al. 2020).

\section{Discussion}

Students' narratives point to ways in which instructors can further conceptualize and plan the learning and teaching of oral presentations while incorporating inclusive pedagogical principles in their instructional strategies. Participants mentioned that they would learn better and would experience less apprehension if they received precise instructions regarding the assignment, if they were taught explicitly emotional self-regulation, and if they could practice more frequently. It is to be noted that scholars have underscored that providing precise instructions for assignments, and paying attention to the emotional dimension of learning, fosters inclusive learning (Grier-Reed and Willliams-Wengerd 2018; Orr and Hammig 2009). While it is commendable that students aspire to practice more for the presentation, it is not always possible to use class time for rehearsal. Thus, in the weeks prior to the lightning talk presentation, it can be beneficial for students to know the precise extent of class time dedicated to preparation. If there is time set aside for practice, students should be informed that this time may not suffice to be fully prepared. In sum, it is important to highlight that, despite the stressful nature of presenting in front of classmates, practicing in advance can ease the process, and may have to take place outside of class time.

While memorization can be a challenge, we maintain that it is beneficial to present without support material to learn how to maintain eye-contact while voicing a compelling statement. We propose an inclusive pedagogical strategy that can foster memorization skills: the scaffolding of the duration of the lightning talk. Scaffolding is an inclusive pedagogical tool (Silver, Bourke, and Strehorn 1998), and students can start by learning a personal script of one minute and gradually increasing the duration throughout a course or program. Given that two thirds of the students underestimated the preparation time required, and practiced their oral presentations for one to three hours, instructors should proactively inform students that frequent practice and memorization will require several hours. Participants also shared that they would have liked to have the option of presenting alone or in a small group, a suggestion that aligns with the inclusive teaching principle of enabling students to choose several modes of expression (Zeff 2007). As suggested by Orr and Hammig (2009), videotaped presentations can promote universal design and should be offered as a submission option for the lightning talk. Nonetheless, the ability to speak in front of an audience is valuable in several professional settings. Hence, in addition to the possibility of submitting a videotaped presentation, we also suggest that students should have the choice of presenting in class in front of a small group or the whole class.

Despite the nervousness associated with oral presentations, participants clearly reported four areas of 
growth and development: critical thinking skills and creativity, adaptability and flexibility of communication skills, personal and professional self-confidence, and advocacy skills. These competencies can facilitate the transition of college and university graduates from their role as students to that of confident professionals working in their respective fields. Such competencies can also benefit adult learners, as they engage in professional development initiatives and programs.

\section{Conclusion}

The findings do not constitute an objective assessment of learning goals or teaching efficacy and cannot be generalized to all learning environments. Nevertheless, the insights provided by the students remain relevant for instructors who aspire to cultivate an inclusive classroom while fostering public speaking skills. Being prepared to effectively and appropriately communicate ideas is a transferrable skill across multiple professional contexts. In this study, we mobilized the pedagogy of the lightning talk to foster public speaking skills along with advocacy and literacy skills.

Several areas of inquiry can be further explored to capture promising, inclusive pedagogical practices that may help students develop their public speaking skills. There is room to investigate how incremental goals and inclusive pedagogical practices support public speaking skills for students with various pre-university degree preparation, language proficiency levels, and migration status across disciplines. Ultimately, having strong oral communication skills facilitates speech in everyday life, as well as event-specific speeches, which can determine the ability of our students to feel confident when they wish to present their point of view, be heard, leave their mark, and make an impact in their professional and civic lives. Students' perspectives illustrate how instructors can better prepare their students for oral presentations, expand the modes of delivery in a course, and encourage self-reflection about the learning process and the competencies developed.

\section{Acknowledgement}

We would like to thank all the students who participated in this study.

\section{Funding}

We would like to acknowledge that this research project was funded by a Ryerson University Learning \& Teaching Grant (2019).

\section{ORCID}

Johanne Jean-Pierre (D) http://orcid.org/0000-0003-4451-7098

Sabrin Hassan (D) http://orcid.org/0000-0003-2992-9676

Asha Sturge (D) http://orcid.org/0000-0002-9749-4910

\section{References}

Bamberger, Mabry. L. 2019. RealWorld Evaluation: Working under Budget, Time, Data, and Political Constraints. 3rd ed. Thousand Oaks, CA: Sage.

Barry, S. 2012. "A Video Recording and Viewing Protocols for Student Group Presentations: Assisting Self-Assessment through a Wiki Environment." Computers \& Education 59 (3):855-60. doi: 10.1016/j.compedu.2012.04.008.

Cox, A., and L. Marris. 2011. "Introducing Elevator Speeches in the Curriculum." Journal of Education for Library and Information Science 52 (2):133-41.

De Grez, L., M. Valcke, and I. Roozen. 2012. "How Effective Are Self- and Peer Assessment of Oral Presentation Skills Compared with Teachers' Assessments?" Active Learning in Higher Education 13 (2):129-42. doi: $10.1177 / 1469787412441284$.

Grier-Reed, T., and A. Williams-Wengerd. 2018. "Integrating Universal Design, Culturally Sustaining Practices, and Constructivism to Advance Inclusive Pedagogy in the Undergraduate Classroom.” Education Sciences 8 (4):167. doi: 10.3390 .

Gwee, S., and H. L. Toh-Heng. 2015. "Developing Student Oral Presentation Skills with the Help of Mobile Devices." International Journal of Mobile and Blended Learning 7 (4):38-56. doi: 10.4018/IJMBL.2015100103.

Hu, G., and Y. Liu. 2018. "Three Minute Thesis Presentations as an Academic Genre: A Cross-Disciplinary Study of Genre Moves." Journal of English for Academic Purposes 35:16-30. doi: 10.1016/j.jeap.2018.06.004.

Jarvis, G. 2004. "Oral Presentations in Higher Education: Key Issues." Investigations in University Teaching and $\begin{array}{llll}\text { Learning } & 2 & \text { ( } 1 \text { ): }: 56-9 . \quad \mathrm{doi}:\end{array}$ 10.1080/02602938.2017.1303032.

Jean-Pierre, J.,. S. Hassan, A. Sturge, K. Gharabaghi, M. Lewis, J. Bailey, and M. Panitch. 2020. "Poised to Advocate: The Pedagogy of the Lightning Talk in Child and Youth Care Education." International Journal of Child, Youth and Family Studies 11 (3):108-25. doi: 10.18357/ ijcyfs113202019703.

Klentzin, J. C., E. B. Paladino, B. Johnston, and C. Devine. 2010. "Pecha Kucha: Using "Lightning Talk" in University Instruction.” Reference Services Review 38 (1):158-67. doi: 10.1108/00907321011020798.

Liang, H.-Y., and B. Kelsen. 2018. "Influence of Personality and Motivation on Oral Presentation Performance." Journal of Psycholinguistic Research 47 (4):755-76. doi: 10.1007/s10936-017-9551-6.

Moulton, S. T., S. Turkay, and S. M. Kosslyn. 2017. “Does a Presentations Medium Affect Its Message? PowerPoint, Prezi, and Oral Presentations.” Plos One 12 (7):e0178774. doi: 10.1371 /journal.pone.0186673.

Murillo-Zamorano, L. R., and M. Montanero. 2018. "Oral Presentations in Higher Education: A Comparison of the Impact of Peer and Teacher Feedback." Assessment \& 
Evaluation in Higher Education 43 (1):138-50. doi: 10.1080/02602938.2017.1303032.

Murphy, K., and S. Barry. 2016. "Feed-Forward: Students Gaining More from Assessment via Deeper Engagement in Video-Recorded Presentations." Assessment \& Evaluation in Higher Education 41 (2):213-27. doi: 10.1080/02602938.2014.996206.

Orr, A. C., and S. B. Hammig. 2009. "Inclusive Postsecondary Strategies for Teaching Students with Learning Disabilities: A Review of the Literature." Learning Disability Quarterly 32 (3):181-96. doi: 10.2307/27740367.

Pagana, K. D. 2013. "Ride to the Top with a Good Elevator Speech." American Nurse Today 8 (3):14-6.

Ritchie, S. M. 2016. "Self-Assessment of Video-Recorded Presentations: Does It Improve Skills?" Active Learning in Higher Education 17 (3):207-21. doi: 10.1177/ 1469787416654807.
Saldaña, J. 2016. The Coding Manual for Qualitative Researchers. 3rd ed. Thousand Oaks, CA: Sage.

Silver, P., A. Bourke, and K. C. Strehorn. 1998. "Universal Instructional Design in Higher Education: An Approach for Inclusion." Equity \& Excellence in Education 31 (2):47-51. doi: 10.1080/1066568980310206.

Simpson, D. 2016. ““'Going up?” A Sport Psychology Consultant's Guide to the Elevator Speech." Journal of Sport Psychology in Action 7 (2):109-20. doi: 10.1080/21520704.2016.1182091.

Vahid, A. 2017. "Understanding the Role of Likeability in the Peer Assessments of University Students' Oral Presentation Skills: A Latent Variable Approach." Language Assessment Quarterly 14 (4):398-419. doi: 10.1080/15434303.2017.1393820.

Zeff, R. 2007. "Universal Design across the Curriculum." New Directions for Higher Education 2007 (137):27-44. doi: 10.1002/he.244. 